\title{
Experimental Evaluation on Grinding Texture on Flank Face in Chamfer Milling of Stainless Steel
}

\author{
Xian-Li Liu ${ }^{1}$, Jin-Kui Shi ${ }^{1}$, Wei ji ${ }^{1,2^{*}}$ (D) and Li-Hui Wang ${ }^{2}$
}

\begin{abstract}
The surface quality of chamfer milling of stainless steel is closed related to the products of 3C (Computer, Communication and Consumer electronics), where a cutter is a major part to achieve that. Targeting a high-quality cutter, an experimental evaluation is carried out on the influence of grinding texture of cutter flank face on surface quality. The mathematic models of chamfer cutter are established, and they are validated by a numerical simulation. Also the grinding data are generated by the models and tested by a grinding simulation for safety reasons. Then, a set of chamfer cutting tools are machined in a five-axis CNC grinding machine, and consist of five angles between the cutting edge and the grinding texture on the $1 \mathrm{st}$ flank faces, i.e., $0^{\circ}, 15^{\circ}, 30^{\circ}, 45^{\circ}$ and $60^{\circ}$. Furthermore, the machined cutting tools are tested in a series of milling experiments of chamfer hole of stainless steel, where cutting forces and surface morphologies are measured and observed. The results show that the best state of both surface quality and cutting force is archived by the tool with $45^{\circ}$ grinding texture, which can provide a support for manufacturing of cutting tool used in chamfer milling.
\end{abstract}

Keywords: Grinding texture, Chamfer cutter, Cutting force, Surface quality

\section{Introduction}

In modern 3C industry (Computer, Communication and Consumer Electronics), the metal shell provides a better experience in both touch and visual than plastic one. Many companies have launched the products with metal shell since 2013, e.g., Apple, Samsung, HTC, Huawei, Lenovo, OPPO, Xiaomi and Meizu [1]. Here, the machining process plays a key role in the delivery of the 3C products with high machining quality, especially with surface quality. During machining, high-quality surface is usually obtained by optimising cutting parameters and tool geometrical parameters [2]. Among other factors, the grinding texture on tool flank face is closely related to the surface quality, due to it is in contact with finish surface directly during machining.

Targeting the suitable parameters of grinding texture generating good surface quality in chamfer machining, a

\footnotetext{
*Correspondence: weiji@hrbust.edu.cn

1 Harbin University of Science and Technology, Harbin 150080, China

Full list of author information is available at the end of the article
}

series of experiments are carried out in this research. The remainder of this paper is organised as follows. Literature review is described in Section 2, followed by the manufacture of the chamfer cutting tool in Section 3, including mathematic models, numerical simulation, grinding simulation, etc. Experiment setups are presented in Section 4, and the experimental results of cutting force and surface quality are illustrated in Section 5. Finally, Section 6 concludes this paper.

\section{Literature Review}

There are many factors influencing the surface quality of machined parts generally, e.g., geometrical parameters of chamfer tool, material properties, cutting parameters, coolant, and lubricants, etc.

Geometrical parameters of the chamfer tool influence the machined surface quality directly. Xiong et al. [3] analysed the influence of point appearance of cemented carbide cutting tools on quality of the machined surface. To improve the surface quality, the wiper technique was employed in super long rod processing by Lai et al. [4]. 
Wang et al. [5] analysed the effects of rake angle and flank angle of the tool on machined surface roughness of potassium dihydrogen phosphate crystal in diamond turning. Jiang et al. [6] introduced that the comparison test of surface quality and tool wear was carried out using three polycrystalline diamond (PCD) tools with different grinding surface quality, and flank surface quality of PCD cutting tool has a big influence on machined surface quality, but has less effects on cutting tool's life. The effect of the tool flank wear $\left(V_{B}\right)$ on the surface roughness and cutting force was studied by Wu et al. [7], and the mechanism of production was discussed. Dong et al. [8] reported that the machined surface quality can be improved by using a designed diamond tool sharpness.

Textured surface was applied to cutting tools to improve their performances, e.g., cutting force [9], cutting temperature [10], anti-adhesiveness [11, 12], and tool wear [13]. Obikawa et al. [14] proposed a set of experimental comparison of four types micro-textured coated tool in turning of an aluminium alloy A6061-T6, as a result of which, friction force and the coefficient of friction were reduced. Deng et al. [15] proposed three carbide tools with textured rake-face with filled with solid lubricants in dry cutting. Their experiments demonstrated the tool performances were improved comparing to cutting tool without textures, where cutting force, cutting temperature, and friction coefficient are reduced. They also applied a carbide tool within the three tools in dry cutting of titanium alloys Ti- $6 \mathrm{Al}-4 \mathrm{~V}$, and the similar results were obtained [16]. The textured $\mathrm{Al}_{2} \mathrm{O}_{3} /$ $\mathrm{TiC}$ ceramic tool were also tested in dry cutting of hardened steel, and the result showed that the chip morphology and chip curl were changed, and that the tool wear was reduce by the textured self-lubricated tools [17]. Xie et al. [18] proposed a set of experiments using cutting tool with a non-coated micro-grooved rake face, and the results showed cutting temperature and cutting force were reduced significantly. Fatima et al. [19] proposed a turning inserts with structured rake-flank face used in machining of AISI/SAE 4140. In their experiments, the textured cutting tools showed better performances in. reducing compress ratio, cutting force, cutting temperature, and flank face wear. Sugihara et al. [20] designed a kind of cubic boron nitride with textured flank face which was used in high-speed machining of Inconel 718, a kind of superalloys. As a result of their experiments, a cutting tool with micro grooves orthogonal to cutting edge set back from the cutting edge significantly showed the best cutting edge state.

Cutting parameter selection is an important factor to improve the surface quality. Zou et al. [21] developed a new cutting tool using a hot-pressed technology, and evaluated the cutting performance using a standard orthogonal array experiment. Fan et al. [22] reported the optimised cutting parameters used in turning of Inconel 718 with PVD coated carbide tool, improving the surface quality. Kong et al. [23] analysed the impact of high speed milling parameters on the surface roughness, residual stress, and the distribution of residual stress, respectively, in a series of single factor experiments. Hu et al. [24] proposed a selection method of cutting parameters to improve the surface quality in precision and ultraprecision machining. Sonawane et al. [25] presented an optimisation method of the machining parameters by using a central composite design with each variable taken at five levels in terms of the design constraints, e.g. product thickness, product inclination and cutter orientation. In addition, Mustea et al. [26] analysed the roughness and hardness through investigating the influence of cutting parameters (cutting speed, feed rate and cutting depth) on the surface quality machined in turning of AZ61 magnesium alloy. Mgwatu [27] proposed an integrated optimisation models of machining parameters considering tool wear and surface quality in multi-pass turning operations. Chirita et al. [28] used three cooling methods, e.g., dry cutting, minimum quantity lubrication and compressed air, to investigate the influences of cooling systems on surface quality of magnesium alloy parts. Salisbury et al. [29] found a way of mapping grinding wheel topography on the workpiece via a geometric-kinematic model in a single-pass surface grinding process. In their model, table speed, wheel speed, wheel topography and original workpiece surface texture were concerned.

From the literature survey, many factors related to surface quality of the machined parts have been addressed, e.g., geometrical factor, micro-texture, and cutting parameters. However, there are few reports concerning the grinding texture on cutting tool flank face, in particular in the chamfer machining of hole. Therefore, this paper is focused on the relationship between the machined surface and grinding texture on flank face in the chamfer milling of stainless steel.

\section{Manufacturing of Cutting Tool}

Manufacturing of chamfer cutting tool starts with the establishment of the mathematical models including rake face, 1st flank face and 2nd flank face. Following that, the simulation of the models is carried out for the safety reason, and then machining process is driven by the simulated models.

\subsection{Mathematical Model of Cutting Tool}

There are two methods applied to establishment of cutting tool models, analytic geometry and differential geometry [30]. Analytic geometry is employed to establish the mathematical models of the cutting tool. 


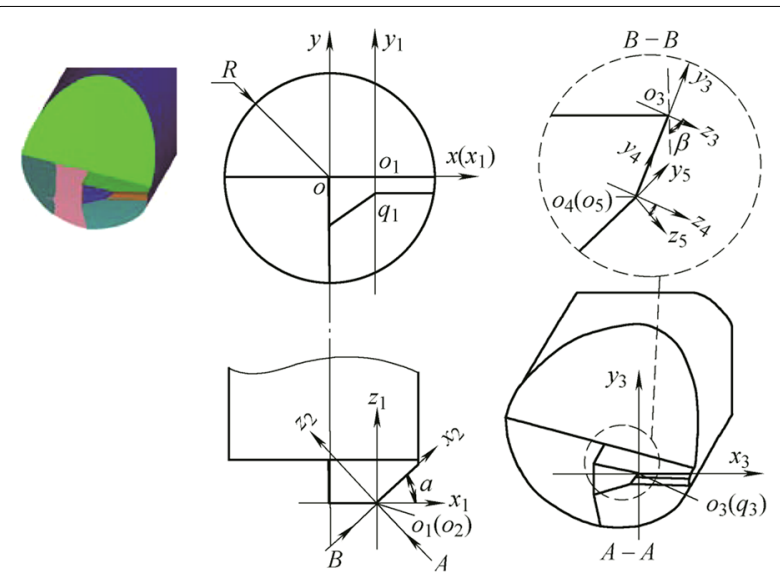

Figure 1 Transformation of coordinate systems for cutting edges

Coordinate system $x y z$ of cutting tool model is built firstly, where $z$ axis is the central axis of cutting tool, and the tool tip is the origin of the system $x y z$ (Figure 1). The coordinate system $x_{1} y_{1} z_{1}$ can be obtained by the translation $t_{x}$ of $x y z$ along $x$ axis. The system $x_{2} y_{2} z_{2}$ can be generated by rotation of $x_{1} y_{1} z_{1}$ around $y_{1}$ through an angle of $\alpha$. By rotating $x_{2} y_{2} z_{2}$ around $x_{2}$ axis through an angle of $\beta$, the system $x_{3} y_{3} z_{3}$ can be obtained. The system $x_{4} y_{4} z_{4}$ is generated after moving $x_{3} y_{3} z_{3}$ along $y_{3}$ axis by $t_{y}$. Finally, the system $x_{5} y_{5} z_{5}$ is obtained by rotating $x_{4} y_{4} z_{4}$ around $x_{4}$ axis through an angle of $\eta$. The transformation matrix $\boldsymbol{M}$ between $x y z$ and $x_{5} y_{5} z_{5}$ is calculated by Eq. (1):

$$
\begin{aligned}
M & =M_{x t} \times M_{y \eta} \times M_{x a} \times M_{y t} \times M_{x \beta} \\
& =\left[\begin{array}{cccc}
\cos (\alpha) & \sin (\alpha) \sin (\beta+\eta) & -\sin (\alpha) \cos (\beta+\eta) & 0 \\
0 & \cos (\beta+\eta) & \sin (\beta+\eta) & 0 \\
\sin (\alpha) & -\cos (\alpha) \sin (\beta+\eta) & -\cos (\alpha) \cos (\beta+\eta) & 0 \\
t_{x} \cos (\alpha) & t_{x} \sin (\alpha) \sin (\beta+\eta)+t_{y} \cos (\eta) & -t_{x} \sin (\alpha) \cos (\beta+\eta)+t_{y} \sin (\eta) & 1
\end{array}\right],
\end{aligned}
$$

where $M_{x t}$ is a transformation matrix from $x y z$ to $x_{1} y_{1} z_{1}$, $\boldsymbol{M}_{x \boldsymbol{}}$ a transformation matrix from $x_{1} y_{1} z_{1}$ to $x_{2} y_{2} z_{2}, \boldsymbol{M}_{x \alpha}$ a transformation matrix between $x_{2} y_{2} z_{2}$ and $x_{3} y_{3} z_{3}, M_{y t}$ a transformation matrix between $x_{3} y_{3} z_{3}$ and $x_{4} y_{4} z_{4}$, and $\boldsymbol{M}_{\boldsymbol{y}}$ a transformation matrix from $x_{4} y_{4} z_{4}$ to $x_{5} y_{5} z_{5}$.

For the chamfer tool, a straight line is utilised as the cutting edge, the model of which is established easily in the system $x y z$, as shown in Eq. (2):

$$
\begin{aligned}
& \left\{\begin{array}{l}
x=x_{o_{1}}+t \times \cos \alpha, \\
y=0, \\
z=t \times \sin \alpha,
\end{array}\right. \\
& a \leq t \leq b \text {, }
\end{aligned}
$$

where $t$ is the parameter of the model, and $a$ and $b$ are the constraints of $t$.

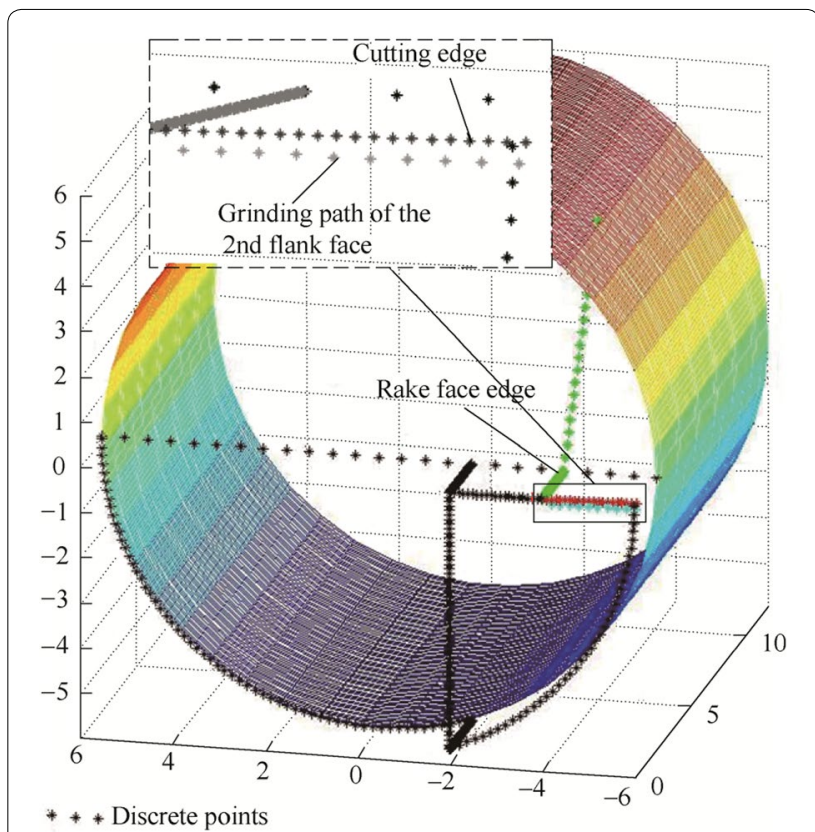

Figure 2 Numerical simulation of chamfering tool

The 2nd flank face is a three-dimensional surface which is constituted by cutting edge and the grinding path of the 2nd flank face. A straight line in $x_{5} y_{5} z_{5}$ (Eq. 3) is selected as the grinding path of the 2nd flank face. Therefore, the path in $x y z$ is calculated by substituting Eq. (3) into Eq. (1):

$$
\left\{\begin{array}{l}
x_{5}=t_{1}, \\
y_{5}=0, \quad c \leq t_{1} \leq d, \\
z_{5}=0,
\end{array}\right.
$$

where $t_{1}$ is the parameter of the model, and $c$ and $d$ are the constraints of $t_{1}$.

\subsection{Numerical Simulation on Cutting Tool Models}

In order to validate the mathematical models (Section 3.1) of chamfer cutting tool, a numerical simulation is carried out in MATLAB, as shown in Figure 2, where there are the face and line, e.g., cutting edge, and 1st flank face between cutting edge and cutting path of the 2nd flank face. Here, the geometries of the chamfer cutting 
Table 1 Geometric parameters of chamfer tool

\begin{tabular}{|c|c|c|c|}
\hline Material & Diameter (mm) & Edge length (mm) & Tool length (mm) \\
\hline K40UF & 12 & 2 & 50 \\
\hline Tooth number/peace & Rake angle $\left(^{\circ}\right)$ & 1st flank angle $\left(^{\circ}\right)$ & 2nd flank angle $\left(^{\circ}\right)$ \\
\hline 1 & 0 & 4 & 15 \\
\hline
\end{tabular}

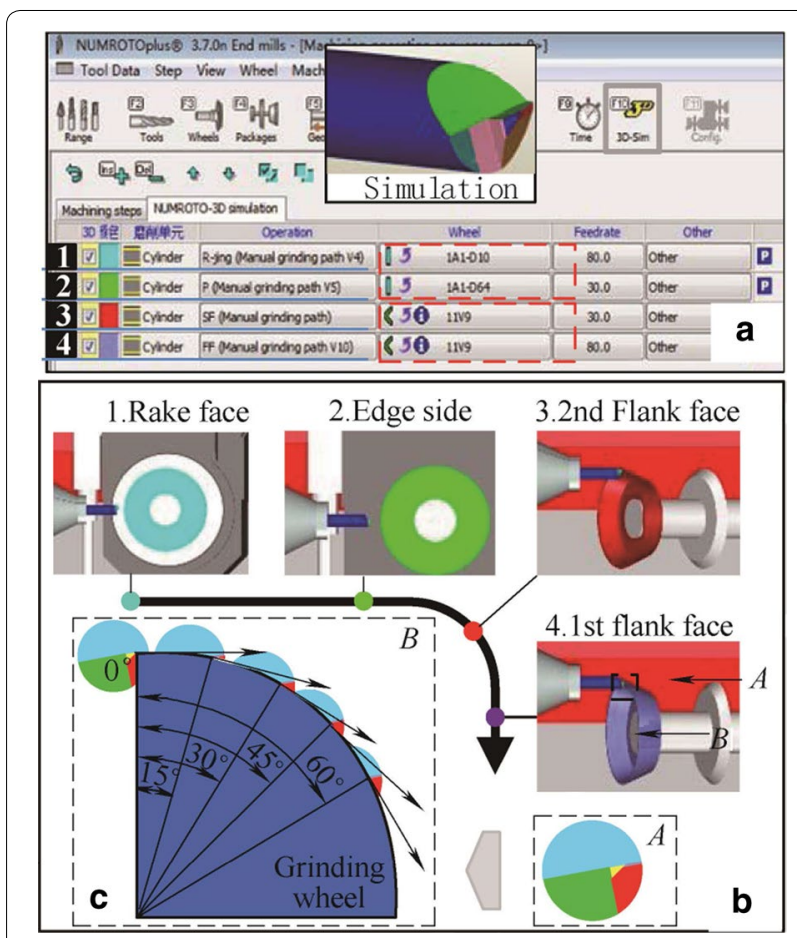

Figure 3 Simulation of grinding process

tool are determined by tool shape parameters $(R, a, b)$ and cutting edge cross-section parameters $(\gamma, \beta)$.

\subsection{Grinding Processes of Cutting Tool}

The geometric parameters of chamfer cutting tool, as shown in Table 1, consist of diameter, edge length, tool length, tooth number, rake angle, the 1st flank angle, and the 2nd flank angle. The grinding processes is planned according to the features of cutting tool, as shown in Figure 3(a), consisting of four steps, i.e., rake angle grinding, edge side grinding, 2nd flank angle grinding, and 1st flank angle grinding. Rake angle grinding and edge side grinding are machined by a straight diamond grinding wheel (grit size: D10, concentration: C100, wheel grinding feed: $0.015 \mathrm{~mm}$ ), whereas the 2nd flank angle grinding and 1st flank angle grinding are machined by a dish cup diamond grinding wheel (grit size: D64, concentration: C100, wheel grinding feed: $0.035 \mathrm{~mm}$ ) (Figure 3b). Also, to generate five kinds of grinding textures on 1st flank face, five grinding strategies are developed (Figure 3c).

The grinding data are generated based on the mathematical models of the tool, and they are imported into NUMROTO software embedded in the grinding machine. After setting up grinding parameters, the simulations are carried out on the four steps accordingly to validate the grinding data, as shown in Figure 3(a), which demonstrates the correctness of the data. Consequently, the cutting tools are machined in a grinding machine, as shown in Figure 4, where Figure 4(a) shows the carbide blank, Figure 4(b) reveals the grinding process in the grinding machine, and Figure 4(c) illustrates the chamfer cutting tool including 1st flank angle, 2nd flank angle, rake face and cutting edge, etc.

Figure 5 depicts the grinded cutting tools with different grinding textures on 1st flank face, where five 1st flank faces, on which there are five angles between cutting edge and the texture line, i.e., $0^{\circ}, 15^{\circ}, 30^{\circ}, 45^{\circ}$ and $60^{\circ}$, are displayed in Figure 5(a)-(e), respectively.

\section{Experimental Setups}

In the test, the chamfers are machined on the drilled holes. A 304 stainless steels used as a mobile case are selected as the test workpiece. Figure 6 depicts the experimental setups. A 3-axis milling machine, VDL-1000E, is selected to carry out the test. Kistler $9257 \mathrm{~B}$ is used to measure the cutting force combining charge amplifier and data acquisition. As the machining parameters, cutting speed is $14.32 \mathrm{~m} / \mathrm{min}$, feed rate is $0.01 \mathrm{~mm} / \mathrm{rev}$, and $a_{p}=0.16 \mathrm{~mm}$, which are employed in real industry.

KEYENCE VHX-1000 digital microscopeis utilised to observe the machined chamfered surface. A white light interferometer, Talysurf CCI PM, is selected to measure the surface roughness of machined chamfer.

\section{Results and Discussions}

The influences of grinding texture on cutting force, surface form and roughness are analysed accordingly in this section.

\subsection{Cutting Force}

Figure 7 shows the influences of grinding texture on the 3 -direction cutting forces of $x, y$ and $z$. With the grinding texture angle from $0^{\circ}$ to $45^{\circ}$, cutting forces of $x, y$ and $z$ 


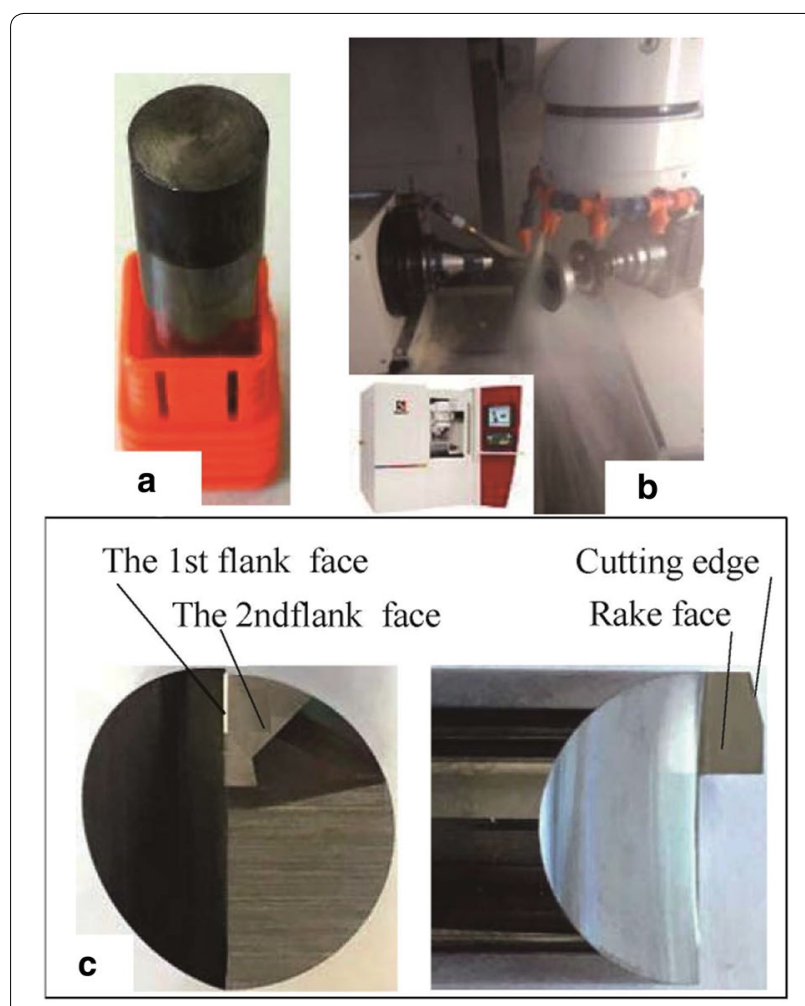

Figure 4 Grinding process of chamfer cutting tool

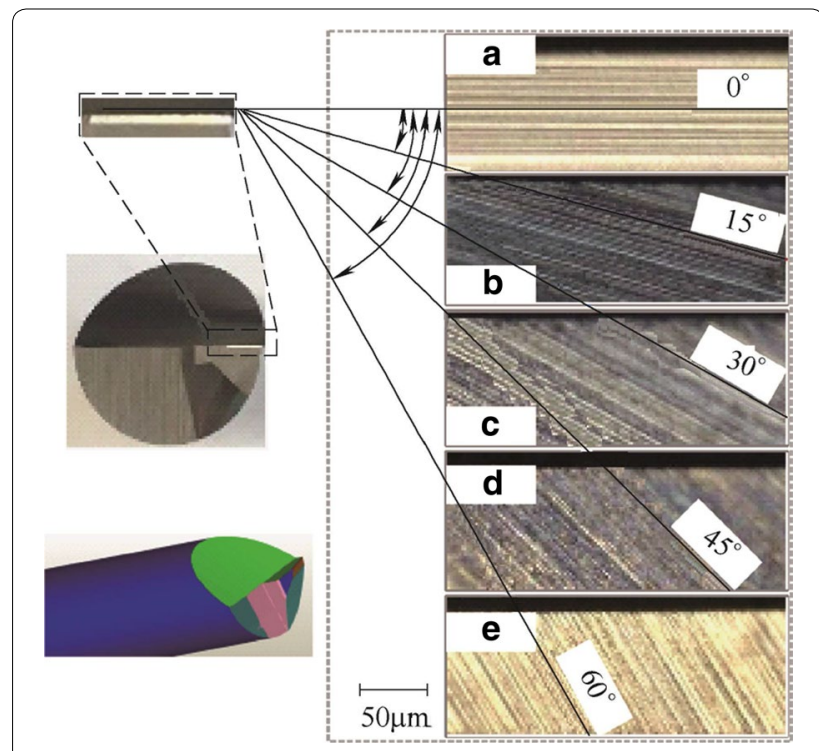

Figure 5 The 1st flank faces

are decreased from $x=205.1 \mathrm{~N}, y=207.5 \mathrm{~N}$ and $z=94 \mathrm{~N}$ to $x=119.6 \mathrm{~N}, y=132.4 \mathrm{~N}$ and $z=67.7 \mathrm{~N}$, respectively. Then the forces are increased to $x=147.1 \mathrm{~N}, y=146.5 \mathrm{~N}$, $z=72.6 \mathrm{~N}$ after the texture angle over $45^{\circ}$. Moreover, the cutting force values of $x$ and $y$ directions are higher than

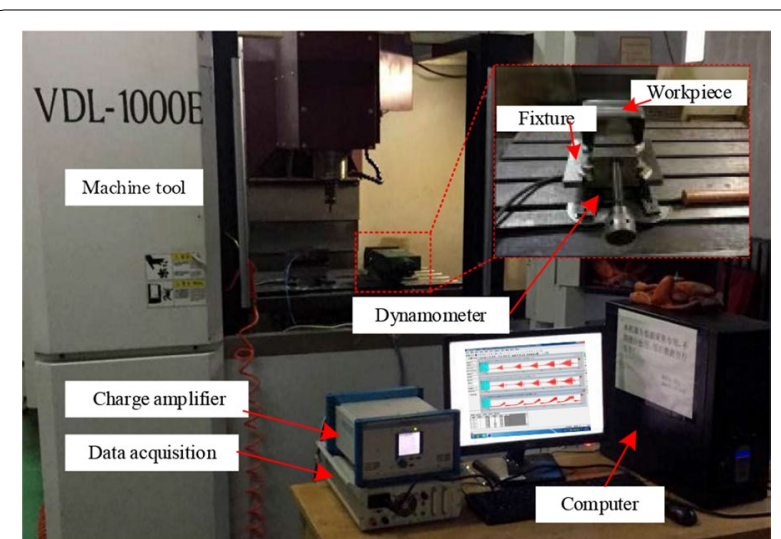

Figure 6 Experiment equipment

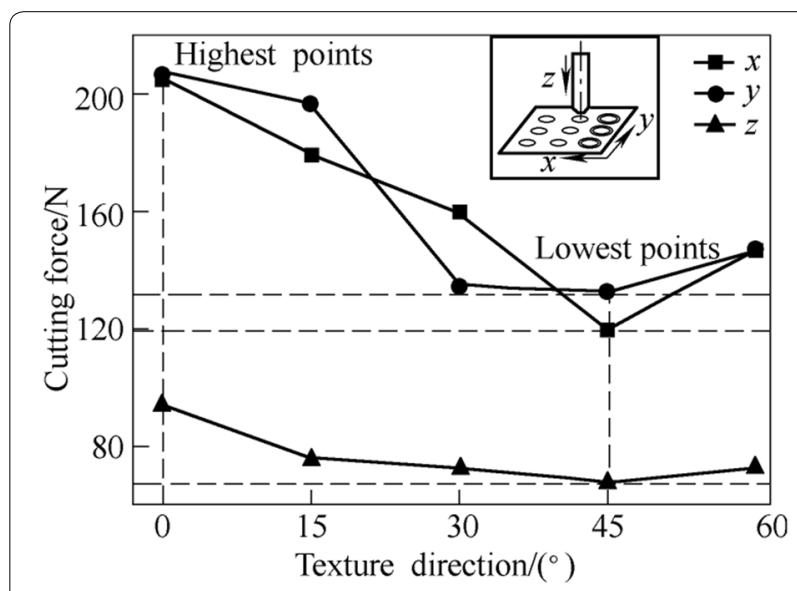

Figure 7 Influence of grinding texture on cutting force

the cutting force values of $z$ direction that changes with in a small range. The cutting forces of $x$ and $y$ directions are similar in trends and values. The lowest cutting force value is generated when the grinding texture equals $45^{\circ}$, and the highest cutting force is at the $0^{\circ}$ grinding texture. According to the results, it is obvious that the cutting forces are influenced by the texture direction.

\subsection{Surface Forms and Roughness}

Figure 8 shows the impact of the grinding texture angles on the machined surface forms, where the burn and the coarse texture are the main defect patterns. Generally, the surface quality is improved as the grinding texture angle is increased from $0^{\circ}$ to $45^{\circ}$. However, the surface quality of machined products is deteriorated gradually when grinding texture is between $45^{\circ}$ to $60^{\circ}$. In Figure $8(\mathrm{a})$, the coarse textures appear from bottom to top of the chamfer, and the burn is also generated. The burn 


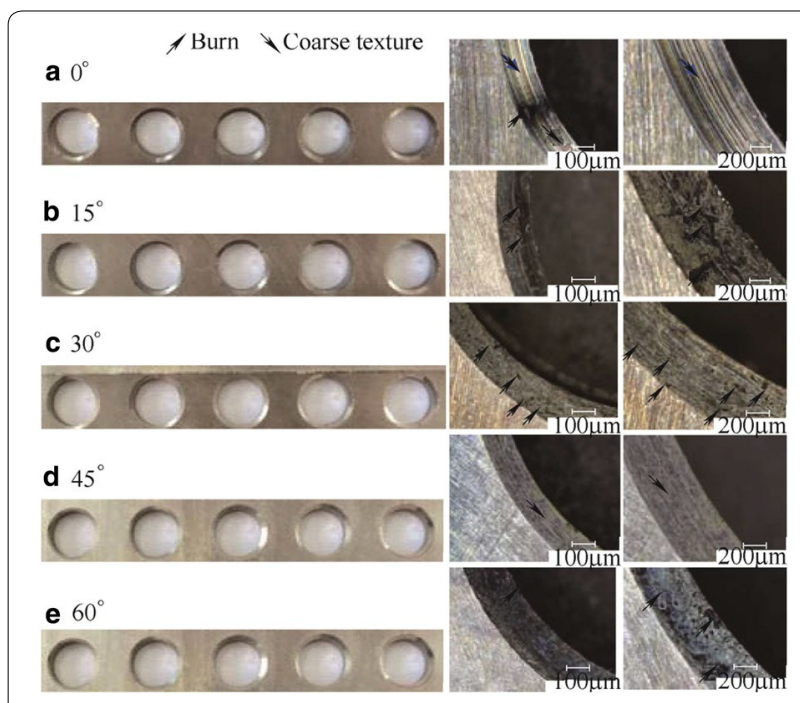

Figure 8 Surface forms of machined chamfers

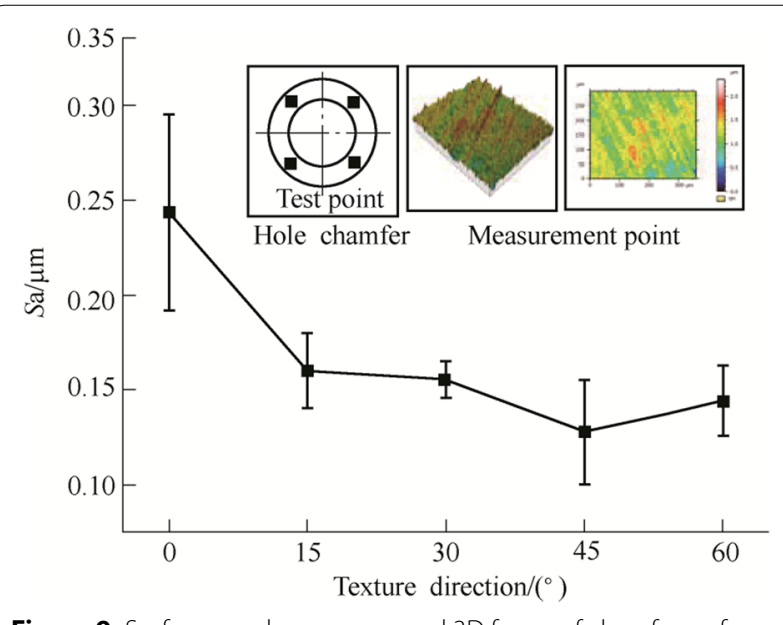

Figure 9 Surface roughness curve and 3D forms of chamfer surface

is the major defect when the grinding texture angle is $15^{\circ}$, and comparing with $0^{\circ}$ texture angle, the coarse texture defect is improved (Figure $8 \mathrm{~b}$ ). The burn spots are fewer at $30^{\circ}$ grinding texture angle than at $15^{\circ}$ angle (Figure $8 \mathrm{c}$ ), and there is no scratch defect. There is no burn spot on the chamfer surface at $45^{\circ}$ grinding texture angle (Figure 8d); however, there is many small coarse texture. When grinding texture angle is $60^{\circ}$, the burns are generated into an area, and they are more than $45^{\circ}$ grinding texture angle (Figure 8e). Therefore, the surface quality is highly influenced by grinding texture, and it is the highest at $45^{\circ}$ grinding texture.

A $3 \mathrm{D}$ roughness criterion, arithmetical mean height $S a$, is utilised to describe the roughness, and it expresses surface quality with higher-accuracy than the $2 \mathrm{D}$ roughness criteria. Figure 9 depicts the surface roughness curve and 3D forms of machined chamfer, and four samples are selected to measure $S a$ to raise the measurement accuracy. $S a$ is decreased with the texture angle raising from $0^{\circ}$ to $45^{\circ}$, however, it is increased after $45^{\circ}$ texture angle. The lowest $S a$ is generated at $45^{\circ}$ texture angle.

The friction type between the flank face of the tools and the workpiece surface is mixed friction. The one part of the friction surface is separated by oil film, and the other part of the friction surface is contacted. The texture directions determine the frictional behaviour and lubricant retention of flank, which effects the cutting force, surface generation and roughness.

\section{Conclusions}

(1) A set of cutting tools with five angles of texture angle, i.e., $0^{\circ}, 15^{\circ}, 30^{\circ}, 45^{\circ}$ and $60^{\circ}$, are modelled, simulated, machined and tested accordingly to evaluate the grinding texture on flank face. Cutting force, surface quality and surface roughness are observed.

(2) The cutting force is decreased with texture angle increasing from $0^{\circ}$ to $45^{\circ}$, and then is increased. The lowest cutting force is achieved at $45^{\circ}$ grinding texture angle.

(3) The burn and the coarse texture are the main defect patterns in chamfer milling of stainless steels. The best surface quality is achieved at $45^{\circ}$ grinding texture.

(4) Surface roughness $\mathrm{Sa}$ is decreased with texture angle increasing from $0^{\circ}$ to $45^{\circ}$, and then is increased. It is obvious that the best state of surface roughness is archived by the tool with $45^{\circ}$ grinding texture.

(5) Combining the results of cutting force, surface quality, and surface roughness, it is obvious that the best machining state is obtained at $45^{\circ}$ texture angle, i.e. the lowest cutting force, the best surface form, and the lowest surface roughness.

\section{Authors' Contributions}

XLL and WJ was in charge of the whole trial; JKS and WJ wrote the manuscript; LHW assisted with sampling and laboratory analyses. All authors read and approved the final manuscript.

\section{Author details}

${ }^{1}$ Harbin University of Science and Technology, Harbin 150080, China. ${ }^{2}$ KTH Royal Institute of Technology, 10044 Stockholm, Sweden.

\section{Authors' Information}

Xian-Li Liu, born in 1961, is a professor at Harbin University of Science and Technology, China. His majors are cutting tool technology and metal cutting.

Jin-Kui Shi, born in 1989, is a master candidate, and he focuses on cutting tool manufacturing technology.

Wei Ji, PhD, born in 1986, is a post doctor at KTH Royal Institute of Technology, Sweden. His major is focused on cutting tool manufacturing technology and process planning. 
Li-Hui Wang, is a professor at KTH Royal Institute of Technology, Sweden. He focuses on process planning, cloud manufacturing, and human-robot collaboration.

\section{Competing Interests}

The authors declare that they have no competing interests.

\section{Funding}

Supported by Heilongjiang Provincial Natural Science Foundation of China (Grant No. QC2016070).

\section{Publisher's Note}

Springer Nature remains neutral with regard to jurisdictional claims in published maps and institutional affiliations.

Received: 25 January 2017 Accepted: 9 August 2018 Published online: 20 August 2018

\section{References}

[1] J Zhou. Intelligent manufacturing - main direction of "Made in China 2025." China Mech. Eng., 2015, 26: 2279-2284.

[2] C H Lauro, L C Brandãcz, T H Panzera, et al. Surface integrity in the micromachining: A review. Rev. Adv. Mater. Sci., 2015, 40: 227-234.

[3] J Xiong, J Zhou. The influence of point appearance of cemented carbide cutting-tools on the quality of the machined surface. J. Yunnan Univ., 2005, 22: 136-139.

[4] P Lai, Y Li. Application of wiper technique in super long rod process. Mach. Tool Hydraul., 2014, 42: 31-33.

[5] J Wang, M Chen, S Dong, et al. Effects of the tool angles on the machined surface quality of KDP crystal in diamond turning. Key Eng. Mater., 2007, 364-366: 297-301.

[6] Z Z Jiang, H T Zhang, M Li. Experiment and study on influence of flank surface quality of PCD Cutting tool on machined surface quality and cutting tool life. Tool Eng., 2006, 40: 24-26.

[7] Z Wu, Y Liu, Y Tang. Effect of tool flank wear on cutting force and surface roughness. Tool Eng., 2005, 39: 37-39.

[8] S Dong, M Zhou, Z Yuan. Effect of workpiece micro-properties on nanometer surface quality. Chinese J. Sci. Instrum., 1996, 17: 396-398.

[9] S Lei, S Devarajan, Z Chang. A study of micropool lubricated cutting tool in machining of mild steel. J. Mater. Process Technol., 2009, 209: 1612-1620. https://doi.org/10.1016/j.jmatprotec.2008.04.024.

[10] Y Lian, J Deng, G Yan, et al. Preparation of tungsten disulfide (WS2) softcoated nano-textured self-lubricating tool and its cutting performance. Int. J. Adv. Manuf. Technol., 2013, 68: 2033-2042. https://doi.org/10.1007/ s00170-013-4827-y.

[11] T Sugihara, T Enomoto. Improving anti-adhesion in aluminum alloy cutting by micro stripe texture. Precis. Eng., 2012, 36: 229-237. doi: http:// dx.doi.org/10.1016/j.precisioneng.2011.10.002

[12] T Sugihara, T Enomoto. Development of a cutting tool with a nano/ micro-textured surface - Improvement of anti-adhesive effect by considering the texture patterns. Precis. Eng., 2009, 33: 425-429. doi: http:// dx.doi.org/10.1016/j.precisioneng.2008.11.004.

[13] T Sugihara, T Enomoto. Crater and flank wear resistance of cutting tools having micro textured surfaces. Precis. Eng., 2013, 37: 888-896. https://doi. org/10.1016/j.precisioneng.2013.05.007.
[14] T Obikawa, A Kamio, H Takaoka, et al. Micro-texture at the coated tool face for high performance cutting. Int. J. Mach. Tools Manuf., 2011, 51: 966-972.

[15] J Deng, Z Wu, Y Lian, et al. Performance of carbide tools with textured rake-face filled with solid lubricants in dry cutting processes. Int. J. Refract. Metals Hard Mater., 2012, 30: 164-172.

[16] Z Wu, J Deng, C Yang, et al. Performance of the self-lubricating textured tools in dry cutting of Ti-6Al-4V. Int. J. Adv. Manuf. Technol., 2012, 62: 943-951.

[17] Y Xing, J Deng, J Zhao, et al. Cutting performance and wear mechanism of nanoscale and microscale textured $\mathrm{Al} 2 \mathrm{O} 3 / \mathrm{TiC}$ ceramic tools in dry cutting of hardened steel. Int. J. Refract. Metals Hard Mater., 2014, 43: 46-58.

[18] J Xie, M J Luo, K KWu, et al. Experimental study on cutting temperature and cutting force in dry turning of titanium alloy using a non-coated micro-grooved tool. Int. J. Mach. Tools Manuf., 2013, 73: 25-36.

[19] A Fatima, PT Mativenga. A comparative study on cutting performance of rake-flank face structured cutting tool in orthogonal cutting of AISI/SAE 4140. Int. J. Adv. Manuf. Technol., 2015, 78: 2097-2106.

[20] T Sugihara, Y Nishimoto, T Enomoto. Development of a novel cubic boron nitride cutting tool with a textured flank face for high-speed machining of Inconel 718. Precis. Eng., 2016.

[21] B Zou, H Zhou, C Huang, et al. Tool damage and machined-surface quality using hot-pressed sintering Ti(C7N3)/WC/TaC cermet cutting inserts for high-speed turning stainless steels. Int. J. Adv. Manuf. Technol., 2015, 79: 197-210.

[22] Y Fan, Z Hao, M Zheng, et al. Study of surface quality in machining nickelbased alloy Inconel 718. Int. J. Adv. Manuf. Technol., 2013, 69: 2659-2667.

[23] J Kong, D Lei, XYue. The influence of high speed milling parameter on workpiece surface quality. Mach. Tool Hydraul., 2007, 35: 80-82.

[24] F Hu, L Zhu, L Dong. Choose suited cutter and cutting parameter, improve the part's surface quality of precision and ultraprecision machining. Light Ind. Mach., 2006, 24: 75-77.

[25] H A Sonawane, S S Joshi. Modeling of machined surface quality in highspeed ball-end milling of Inconel-718 thin cantilevers. Int. J. Adv. Manuf. Technol, 2015, 78: 1751-1768

[26] G Mustea, G Brabie. Influence of cutting parameters on the surface quality of round parts made from AZ61 magnesium alloy and machined by turning. Adv. Mater. Res., 2013, 837: 128-134.

[27] M I Mgwatu. Integrated approach for optimising machining parameters, tool wear and surface quality in multi-pass turning operations. Adv. Prod. Eng. Manag. 2013, 8: 209-218.

[28] B Chirita, G Mustea, G Brabie. A statistical analysis applied for optimal cooling system selection and for a superior surface quality of machined magnesium alloy parts. Proc. Inst. Mech. Eng. Part B J. Eng. Manuf., 2015, 229: 392-408.

[29] E J Salisbury, KV Domala, K S Moon, et al. A three-dimensional model for the surface texture in surface grinding, Part 1: Surface generation model. J. Manuf. Sci. Eng., 2001, 123: 576-581. https://doi.org/10.1115/1.1391427.

[30] W Ji. Research on design and manufacturing of solid carbide ball end mill of "Shape-Performance-Application" integration. Harbin University of Science and Technology, 2015. (in Chinese)

\section{Submit your manuscript to a SpringerOpen ${ }^{\circ}$ journal and benefit from:}

- Convenient online submission

- Rigorous peer review

- Open access: articles freely available online

- High visibility within the field

Retaining the copyright to your article

Submit your next manuscript at springeropen.com 